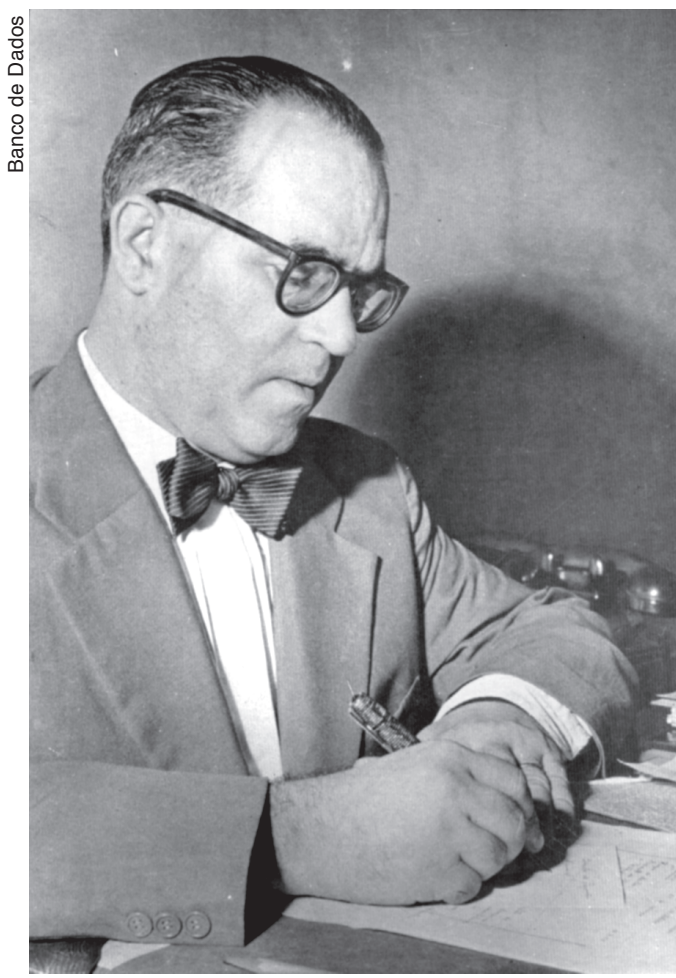

\title{
O tempo às avessas da
} negatividade
rosiana

Foto clássica do escritor Jõão Guimarães Rosa

O problema básico, existencial, equacionado por Guimarães Rosa não é só o do tempo, mas o fato de nós, terrícolas, sermos, na verdade, "nós, tempícolas" ("Evanira!", in Ave, Palavra, p. 39). Como em qualquer dos contos críticos, essa consciência do tempo apresenta-se em estado de "instantaneidade". Segundo Bergson, a instantaneidade implicaria duas coisas: uma continuidade de tempo real e um tempo-espacializado (1). Este último se contrapondo aøeal pelo fato de comportar pontos em cuja linha simbólica - descrita por um movimento - é capaz de fazer surgir "os instantes". A teoria bergsoniana preocupa-se com a idéia de simultaneidade, não só de "dois instantes" mas de "dois fluxos". Assim, o filósofo chama simultâneos "dois fluxos exteriores que ocupam a mesma duração, pelo fato de se juntarem, um e outro, na duração de um terceiro que é o nosso" (2). Noutras palavras, tal duraçãođurée) só vira nossa, de modo consciente, "quando a nossa consciência não enxerga nada além de nós mesmos, e quando a nossa atenção abrange os três fluxos num só ato indivisível” (3). Preocupado com a Energia Espiritual advinda de um Tempo Único, Henri Bergson acreditou que "nossa vida precisa achar, nas suas qualidades, finalmente, aquele tempo fundamental" (4)Qualidadequalificávelenãoquantidademensurável-destacadapelamarginália de Rosa -, essa busca interior deverá se circunscrever na unidade de um tempo impessoal, na idéia simples de um tempo comum a todas as coisas. Nele, "haveria bastantes consciências múltiplas saídas da nossa, semelhantes à nossa, às quais
HÉCTOR OLEA é

arquiteto, poeta e ensaísta. É o tradutor da versão hispanoamericana de Macunaíma de Mário de Andrade (Barcelona, Seix Barral), de Obra Escogida de Oswald de Andrade (Caracas, Biblioteca Ayacucho) e Mbopoeta-vinte textos de Guimarães Rosa (no prelo).

O presente ensaio é o capítulo VIII de um aprofundado estudo sobre o estatuto de negatividade inerente ao processo de composição de João cesso de composição de João partida alicerçado em vasta pesquisa nos originais, marginália e volumes da biblioteca-espólio do autor no Instituto de Estudos Brasileiros da USP. 
1 Henri Bergson, Durée et Simultaneité (à Propos de la Théorie d'Einstein), $\mathrm{Pa}$ ris, Félix Alcan, 1923, p. 69

2 Idem, ibidem, p. 68

3 Idem, ibidem

4 André Cresson, Bergson, sa Vie, son CEuvre, 1947, p. 131. O sublinhado pelo escritor brasileiro no seu exemplar (IEB/USP) mostra o seu grande interesse or esta concepção filosófica do tempo.

5 Henri Bergson, op. cit., pp. 59-60.

6 O texto básico da tese é "Páramo". Os números en"Pa parênteses se referen módulos pesquisado nos quais foi dividido "conto". O primeiro número diz respeito às 22 páginas da primeira edição (Estas Estórias, Rio de Janeiro, José Olympio, 1969, pp. 177-98) último, depp. à sentença, módulo lexical ou palavra, cortada segundo a própria seqüência do escrito rosiano.

7 Henri Bergson, op. cit., p. 61.

8 Idem, ibidem, p. 62.

9 Apud André Cresson, op. cit., p. 132 nos encarregamos de fazer a cadeia através da imensidão do universo e de testar, pela identidade das suas durações internas, a contigüidade das suas experiências interiores" (5). Saturado desse assunto essencial para sua existência, o protagonista de "Páramo" condensará num simples módulo (16.63) (6) toda esta idéia dupla, ora pontual, ora maquinal, daquele estado universal de "instantaneidade". Esse é o tempo comum a todos nós, e é interrogativo porque hipotético: "ponto e instante efêmeros na cadeia movente?". Com a evidência dos trechos sublinhados na sua biblioteca, o Rosa-leitor parece traduzir em questões e questionamentos estes tópicos bergsonianos.

Voltando à temporalidade do conto crítico, o que Guimarães Rosa postula não é a continuidade do sintagma narrativo, mas a contigüidade do paradigma poético. Não se trata, contudo, de um tempo único, mas fortemente personificado. $\mathrm{O}$ modo com que ele opera, de abismo em abismo e apoiando-se contra o Nada, diz bem do processo seqüencial em que o texto de Rosa sucede. $\mathrm{O}$ autor, em outro dos textos referidos que esboçam o seu processo de composição, menciona essa operação temporal, universal mas ao mesmo tempo tão pessoal, que reflete naquelas suas "lagoas" mentais, dizendo: "- Eu sou minha própria lacuna, e todas..."(“Quemadmodum”, in Ave, Palavra, p. 135). A mais fraca luz de memória ilumina o problema bergsoniano daqueles obscuros nexos "com um olvido perpetuamente renovado daquilo que não é o movimento imediatamente anterior". Sem sombra de dúvida, para esta filosófica leitura plural do tempo enquanto interiorização seria “impossível imaginar ou conceber um traço de união entre o antes e o depois, sem um elemento de memória e, por conseguinte, de consciência" (7).

Bergson prefere aceitar a impossibilidade de se falar de uma "realidade durável", não sem antes nela introduzir "a consciência". Para o filósofo, o tempo real (aquele que faz a essência da vida) é la durée. A “duração” seria o verdadeiro tecido da realidade. Esta perpetuamente se transformando e sem nunca chegar a ser algo pronto; posto que "a duração é, na essência, uma continuação daquilo que não é mais naquilo que é” (8). Quer dizer, não se pode conceber um tempo sem representá-lo percebido e vivido; duração implicando, pois, consciência. Com efeito, nesse tempo bergsoniano percebido em instantes autônomos, vivido num arquipélago cósmico de ilhas de tempo dispersas no espaço, a realidade seria, precisamente, a de negar o "tempo", questionando-o criticamente. Amiúde, nos seus contos, Rosa insiste nessa configuração duvidosa do tempo, dando-lhe, ainda, uma ênfase interrogativa. Ora em "Páramo", onde o narrador indica uma crise que lhe vem "conscientemente" (2.2), chegando a se perguntar, inclusive, se "aquilo durou horas?" (5.38); ora no Grande Sertão: Veredas, onde o argumento é reforçado pela dúvida de Riobaldo: “Tempo que me mediu. Tempo?" (p. 445).

É na memória que la durée se mostra. Contudo, para o pensamento bergsoniano, cindido entre matéria e memória, a verdadeira memória não é uma função do cérebro. Em princípio, a memória tem de ser uma faculdade absolutamente independente da matéria. Assim, para o filósofo, a Energia Espiritual é uma realidade; portanto, só pelos fenômenos da memória o homem é capaz de entrar em contato experimentalmente com o espírito. Essa experiência seria, então, segundo exemplificaríamos com a circunstância do protagonista de "Páramo", testemunho de "uma operação encoberta" pela "saudade que a gente nem sabe que tem" (14.30). Uma tal realidade da memória enquanto diretriz de criatividade ou escolhas jamais é pessoal, mas interna. No caso rosiano, essa íntima temporalidade dos seus escritos é, além do mais, algo semelhante a um daimon imemorial, em cujo "tempo universal", embora hipotético, se cria a linguagem de todas suas invenções.

Dessa forma, o tempo no conto crítico não é unidimensional ou sucessivo, mas simultâneo. É contíguo e não contínuo. Bergson diz: "É a memória, com o seu desejo corretivo, que torna o passado e o futuro reais, criando, por conseguinte, a verdadeira duração e o verdadeiro tempo" (9). Em textos como "Páramo", esse "desejo corretivo" - caráter crítico do que se conta - viria sublinhar aquela possibilidade hipotética que fica "além do 
Lethes, o rio sem memória" (1.17). A verdade de Rosa é aléthica, ficando, portanto, muito além do infernal fluxo dessas águas passadas. O tempo implicado no próprio nome de Riobaldo não tem possibilidades de "sucesso" perante a passagem do tempo real; a falta de sucessão do seu caráter "baldio" é, de outro modo, a fluidez mesma da nossa erma vida interior. O "homem humano" (Grande Sertão: Veredas, p. 460) dessa temporalidade específica é simultaneamente, enquanto ser paradoxal, a certeza absoluta em diversos mundos e, de maneira concomitante também, a travessia absolutamente incerta em diferentes espaços. Como propõe Rosa nesse espaço crítico dos seus contos, "os tempos se seguem ou parafraseiam-se" ("Curtamão", in Tutaméia, p. 34). Eis o caráter contraditório da escrita de Guimarães Rosa. Caráter cujos tempos tornariam latente, em paráfrase hipotética embora imemorial, uma crítica velada ao homem unidimensional da nossa contemporaneidade.

Num trecho de Sartre sobre a temporalidade em William Faulkner, o autor mineiro destacou e sublinhou o seguinte: "Não há evasão do mundo temporal, senão através de êxtases místicos. Um místico é sempre um homem que quer esquecer alguma coisa: o seu ego e, de modo geral, a linguagem ou as representações figuradas" (10). Portanto, na interpretação sartriana, Faulkner estaria propondo que "é preciso esquecer o tempo". O tempo da escrita é um tempo no qual se fabricam ferramentas verbais e é um tempo que se reflete em tais ferramentas. Eis o tempo do escritor norte-americano: um instrumental específico, ad hoc para seus propósitos expressivos. Além disso, Sartre identifica nessa projeção temporal um certo "presente indizível", quase detido, a ponto de naufragar sempre pelas bruscas acometidas do passado; e ainda uma "ordem afetiva", oposta à ordem intelectual e voluntária que é cronológica. Enfim, um conjunto de "lembranças insistentes", obsessões disparatadas e descontínuas, refletindo as intermitências do coração. Em tudo isso parece ecoar a grande constante do "antiintelectualismo" bergsoniano que, em carta ao seu tradutor italiano (11), Rosa atribuíra sempre ao seu trabalho. Caso preferir- mos esse dado convertido em texto auto-referente, trata-se da fixação dele num projeto de "tempo queé a matéria do entendimento" ("Se Eu Seria Personagem”, in Tutaméia, p. 139).

Mais do que um "tempo", no sentido convencional do termo, o que Rosa equaciona no seu conto crítico é um modelo totalizador de cultura (total culture pattern) aproximando-se, assim, de um espírito perdido no tempo. Modelo de anacronia que é, pois, intelectual, mental, engenhoso, genial, espectral, fantasmagórico, sobrenatural, visionário e, sem dúvida alguma, o mais literário dos estados de ânimo. Só uma penetração intensa nesse estado metalingüístico, tão espirituosamente rosiano, dá conta dele a partir da mais pessoal temporalidade instalada em cada um de nós, seus esforçados leitores.

Paradoxal, Guimarães Rosa apela sempre para o tertium quid dialético. Em depoimento perante um entrevistador alemão, o autor definiu-se não como romancista, mas como criador de contos críticos. Ao fazê-lo, Rosa estava frisando os dois pólos que a sua escrita conjuga e cuja resultante ele identificou como sendo um filho bastardo: "a ficção poética e a realidade" (12). Trata-se, por conseqüência, de uma obra de criação que conta, em essência, o seu material. Isto é, "narra" a sua palavra crítica. No caso específico desse projeto literário, para se poder entender essa simbiose entre poesia e realidade, será preciso pensá-lo da maneira mais ficcional possível. Eduardo Portella, outro crítico que privilegiou o caráter dialético da obra rosiana (13) foi quem detectou um trecho-chave para a interpretação da sua obra: “A história não quer ser história. A estória, em rigor, deve ser contra a História" ("Aletria e Hermenêutica", in Tutaméia, p. 3).

A maneira de ser do poema é, em essência, paradoxal. A forma histórica dele se manifestar é contraditória; não é "verdadeiro", porém não é “falso". Quer dizer, "muito embora não esteja nos propósitos do poeta, o poema é uma máquina produzindo anti-história" (14). Noutras palavras, o conto crítico equacionado por Rosa é, antes de mais nada, poema. Se a arte é história no sentido essencial, "interno", será preciso pensar, aqui, a obra de João Guimarães Rosa no sentido da-
10 Jean-Paul Sartre, "LaTemporalité chez Faulkner", in Situations $I$, Paris, Siluations 1047, Paris, 73-5 grifo é de Guimarãe Rosa.

11 Edoardo Bizzarri, J. Guimarães Rosa: Correspondência comoseu Tradutor Italiano, São Paulo, T. A. Queiroz/nstituto, T. A. Queiroz/lnstituto Cultur talo-Brasileiro, 1981, p 58. No seu testemunho, Rosa fala da sua atração pela proposta bergsoniana, sendo paradoxal no que diz respeito ao que diz respeito ao que montagem que motiva, amiúde forçado e racionaldemais. Segundo ele todos os seus livros "em essência, são antiintelectuais - defendem altíssimo primado da intuiçăo, da revelaçăo". Cart de Rio, 25/nov./1963.

12 Günther Lorenz, "Diálogo com Guimarães Rosa", entrevista realizada durante o Congresso LatinoAmericano de Escritores Americano de Escritores Gêno de 1965), in Fortuna Crítica VI, Rio de Janeiro, INL/Civilização Brasileira, 1983, p. 70

13 Eduardo Portella, "A Estória Cont[r]a História", in Jornal do Brasil, 30/dez./ Jornal do Brasil, 30/dez/ 967. Rpt. in Fortuna Crítca, op. cit., p. 198.

14 Octavio Paz, Los Hijos del Limo, Barcelona, Seix Barral, 1974, p. 9. 
quela "tradição intra-histórica", como concebida por Miguel de Unamuno. Com efeito, ao sentido histórico, entendido como sendo uma mera sucessividade sem substância, o pensador basco contrapõe o conceito do "intrahistórico", ou seja, "a dimensão presente de interioridade temporal que há na alma do tempo, sendo, também, a matriz da temporalidade" (15). Essa matriz, dinâmico-espiritual-pessoal, encontra-se encalacrada no interior do tempo. De forma paralela - e como mostram anotações dos seus livros de Unamuno -, a essência perseguida por Rosa não precisa ser procurada na tradição histórica do texto (no corpo do espaço narrativo), mas na tradição intra-histórica do intertexto. Istoé, na alma do tempo detido, da maneira mais poética possível, nos interstícios conscientes da sua leitura crítica, decantada, posterior. Eis aqui a "tradição eterna" vertida pelo poeta-tradutor emboca do anônimo protagonista de "Páramo" (12.29): "minha história interna". O processo latente, nela, é a sua historicidade interna, sedimento da história externa.

Nessa tradição, História e Tempo não são senão a projeção móvel, embora insubstancial, de uma realidade mais aprofundada e detida. Essa essência eterna unamuniana, contudo, nãoé platônica ou contemplativa; elaé biótica, e, sendo vital, "a sua ação" é tão insondável como a própria vida. Torna-se claro que, enquanto conteúdo inconsciente, coletivo, aquela "tradição eterna" seria um tempo universal, negativo, absurdo. A versão ibero-americana concebida por Guimarães Rosa, na profunda interioridade do conto crítico, possui ainda, como tudo nele, uma condição paradoxal. De modo similar à tradição eterna, esse tipo de texto, aliás, "não poderia se assimilar a um Ser diferente do histórico; mas, obviamente, só àquela dimensão da história que, todavia, é a negação do histórico" (16). Em Rosa, o acento ontológico desta problemática literária, mais uma vez, estaria recaindo no pólo da negatividade da sua Poética essencial.

A contradição ontológica essencial dos seres textuais rosianos não é o fato destes se colocarem em dois planos do Ser face à eternidade, porém, a circunstância de existirem duas dimensões contraditórias, necessariamente unidas pelo paradoxo. Primeiro, a exis- tência da angústia da “minha” limitação, além do horror do Nada, limite constitutivo do que Unamuno chama de "ser-se". Segundo, a vontade de totalidade; o que ele considera "querer sê-lo todo", igualmente ameaçada de aniquilamento pela própria dissolução dos limites. O protagonista de "Páramo", à "amarga borda" (5.35) desses limites, procurou se situar perante essa ambígua imensidão de existências totais e também nulas dizendo: "Há um centro em mim mesmo?" (5.36). Assim foi que ele optou pela tradição eterna de um tempo interior. Ao dizer, "queria ser eu" (5.34), o anônimo protagonista de Rosa não faz senão se igualar, em transe similar, àquelas personagens à procura de autor, como Augusto Pérez, o unamuniano ente de Niebla (17) que - em 1913, e antes dos de Luigi Pirandello-já questionava a sua verdade enquanto entidade ficcional. Com efeito, Pérez vai até Salamanca em busca do seu Criador (o qual tinha determinado por escrito a sua morte) e cai aos pés dele, exclamando de joelhos: "-iDon Miguel, por Dios, quiero vivir, quiero ser yo!".

Eis a agonia mais sensível do ser cristão: a do paradoxal ser-se. A sua opção existencial fica em mãos do "e"; da conjunção aditiva que também é adversa. Por isso, esse ser não tem mais remédio que servir, simultaneamente, a dois senhores: ora ao Mundo (temporal), ora a Deus (na eternidade). Sob essa perspectiva filosófica, a "eternidade" vira uma tradição mais intratemporal e intra-histórica do que a somatória dos tempos. Como se pode observar, sempre de maneira intertextual, o texto rosiano teria consciência substancial dessa tradição, dessa escandalosa outridade ou "realidade temporal" que abrange o caráter divino. Ciente dos limites constitutivos da "sua co-realidade" poético-narrativa ficcional, para lhe dar corpo Rosa vive a existência interiorizada do seu conto crítico como se fosse mesmo a sua própria Religião da Linguagem. Afinal, para o pensamento "trágico", que abrange de Pascal a Unamuno, crer em Deus é, em certa medida, criá-lo.

Por outra parte, ao interpretar a estranha "narrativa" que o pensamento existencialista de Albert Camus inocula na interioridade temporal de L'Étranger, Jean-Paul Sartre estabe- 
lece uma diferença básica face à "duração" bergsoniana. A variante lhe é fornecida por esse universal negativo que é o absurdo. Sartre diz: "onde Bergson via uma organização indecomponível, o homem absurdo vê apenas uma série de instantes. A descontinuidade das suas frases cortadas (à la Hemingway) ajusta-se à descontinuidade do tempo" (18). Não é casual que o próprio Sartre chame o seu labor de "Situations". A situação geral desenvolvida nos textos de Rosa bem pode se condensar nisto: "O tempo é o absurdo da sua presença" ("Quemadmodum", in Ave, Palavra, p. 136).

Essa mesma essência negativa impregna de tal jeito a Riobaldo, como a tantos outros protagonistas do "drama" rosiano, que ele próprio confessa-se mergulhado no isolamento total "do vazio do tempo em redor" (Grande Sertão: Veredas, p. 425). Tudo isso nos permite cogitar na estrutura do módulo poético manipulado por Rosa nos mesmos termos em que Sartre percebe a linguagem camusiana. Segundo ele, cada frase d'O Estrangeiro é um presente autônomo; cada frase seria, pois, como uma "ilha de tempo", nítida, sem arestas, "fechada em si mesma". Portanto, a sentença de Camus estaria separada da frase seguinte "por um vazio indestrinçável" (19). As leituras e anotações do escritor fornecem evidência suficiente dos seus propósitos metalingüísticos. Isso repercute constantemente nos seus textos, especialmente naquele onde Guimarães Rosa personaliza-se até no título ("Uai, eu?", in Tutaméia, p. 179). Nele, o autor parece reiterar as palavras sartrianas: "A gente se valendo de tempos vazios".

Irreconciliável face a qualquer engano de tipo realista, e em virtude da sua própria natureza escrita, a arte que se pretender autêntica não tolerará jamais nada anódino, secundário. Essas parecem ser as premissas rosianas para as quais a vida não só é muito perigosa, mas absurda. Nelas, o caráter alusivo-elusivo é inerente à criação, como o próprio jogo. Assim sendo, essa "arte só pode se reconciliar com a sua própria existência, voltando para fora o seu caráter aparencial, o seu próprio vazio interior" (20), o seu absurdo. Estas palavras da teoria estética de Adorno não podem ser estranhas ao âmbito rosiano. Em outros autores da biblioteca de Rosa, como Nicolás Berdiaeff, dá-se a idéia de um tempo existencial, quer dizer, "un temps intérieur, non exteriorisé dans l'espace" (21). Nele, o homem não é senão a interseção desse infinito momento interno que estabelece uma simetria cronológica; tal posição privilegiada lhe permitiria vislumbrar os amplos horizontes de uma plena libertação. Emancipação humana que é a do jugo escravizante, ora da História, ora do Olvido.

A escrita rosiana encontra-se "liberta do fardo da temporalidade", indicou com precisão um suplemento literário hanseático (22). O tempo é sem dúvida o problema mais vital da metafísica e do existencialismo. O ser existencial, como o poeta-tradutor João Guimarães Rosa, vai alternando, dia a dia, os séculos baldios da eternidade entre o jogo da criação e a fatigada esperança num Deus Vacante que se esconde, sempre, entre os interstícios do tempo. Do pólo negativo, a obra de Guimarães Rosa - pelo que se conhece de seus textos e sempre que meditou nesse mínimo intervalo que separa os fados dos fatos -, ela mesma "dissera um não, metafisicado" ("Fatalidade", in Primeiras Estórias, p. 63).

Com efeito, nas entrelinhas tortuosas de seus textos, o autor foi lapidar quando equacionou o seu projeto nos termos de uma Poética da Negatividade; ou seja, de um crítico "ato de não" ("A Benfazeja", in Primeiras Estórias, p. 127). A negatividade desse ato, dialético e totalizador, é uma visão de algum modo mística. É uma ofuscante revelação de imagens pairando no ar rarefeito sob a luz escura dos seus enigmas. Dante a entendeu de forma modelar, ao entrar em contato com as primeiras esferas do Paraíso. Nelas, Beatrice, a belíssima personificação da mais alta revelação possível, significa uma tão ilimitada manifestação de atividade suprema: ela se move de maneira tão repentina, sì subitamente, diz o poeta, do Bem para o Melhor, do Melhor para o Supremo, "que o seu ato não se estende no tempo" (23). Nos seus próprios parâmetros, Rosa introduziu poeticamente conceitos similares a este: "Atrás de torto, o desentortado. Adiante. Todo lugar é igual a outro lugar; todo tempo é o tempo. Aí:
18 "L'Étranger", in Situations II, Paris, Gallimard, 1948 p. 103. Aliás, em livros como Les Mots (As Palavras), Sartre frisa, a parti da infân da infância e da biblioteca do avômaterno, o valor da situações e dos instante marcantes da sua vida $e$ formação, como se estes fossem peças detidas na descontinuidade do tempo. Grifo meu.

19 Idem, ibidem, p. 104. Grifo meu.

20 Theodor W. Adorno, "Es teticismo, Naturalismo Beckett", in Teoría Estética, Madrid, Taurus, 1980 p. 326. Grifo meu.

21 Nicolás Berdiaeff, D l'Esclavage et de la Liberté de l'Homme, Paris, Éditions Aubier, 1946, p. 291.

22 Kurt Mayer-Clason, "Von der Last der Zeitlichkeit befreit", in Welt der Literatur, Hamburgo, 17/ set./1964

23 Par. X, 34, "che'l atto suo per tempo non si sporge". Em "contos críticos" como "Buriti" (Noites do Sertão, p. 336), a divina idéia desse "lugar", o Buriti Bom, é um indício de atemporalidade. Além de comportar, em Maria da Glória, portar, em Maria da Gloria uma guia espiritual para transitar na eternidade, semelhante em todos os de talhes à Beatrice dantiana o Buriti carrega, em si próprio, o peso do "inmudado, maior que os anos". 
as coisas acontecidas, não começam, não acabam. Nem” (“A Estória do Homem do Pinguelo", in Estas Estórias, p. 125).

O tempo é um tecido invisível nestes textos de Rosa. É a urdidura de fios trançados pelos "não-fatos" ("Substância", in Primeiras Estórias, p. 156) sempre poéticos, num sentido, e de fios de "atos de não", onde a substância narrativa rareia, no outro. Em textos como "Páramo", o autor é claro quanto aos seus propósitos, no momento em que outorga à temporalidade toda uma configuração interrogativa: "E-existe mesmo o tempo?" (16.28). O conto crítico, como ele mesmo revelara num dos seus papéis de rascunho originais (24), padece de "cronofobia". Porém, essa circunstância assumida pelo escritor - com "o tempo descendo, parado" ("Entremeio: com o Vaqueiro Mariano", in Estas Estórias, p. 106) enquanto escopo poético - leva-o a uma condensação tal cuja densidade, de tão pesada, é por momentos ilegível. Lembra aquela densa dança do "ato paradisíaco" de Beatrice, acima mencionado. Determinante do projeto literário como um todo, a "imobilizada ação" na qual decorrem os escritos rosianos é o seu próprio moto continuum. Mais do que cronológico, esse espectro crônico projeta a insuportável figura do devir como algo contido, tenso de tanta intensidade e recordação interiorizadas.

Riobaldo o chama o "tempo que fiquei, deslembrado, detido" (Grande Sertão: Veredas, p. 436). Como Dante o fizera antes, Guimarães Rosa nunca pretendeu que se acreditasse de modo unívoco nos seus textos - seja numa escura iluminação na Cordilheira Andina, em "Páramo", seja num vislumbre do jeito demoníaco da divindade no Grande Sertão -, mas que disso se suspeitasse. Sendo partes do relato e também revelações, o autor assinalou que esses atos escritos cumprissem uma função. A dupla. E essa "incerteza paradoxal" é parte do seu desígnio. O tempo real, cronológico ou histórico, dentre muitos possíveis, propõe sempre uma única opção: perto ou longe. Absurdo por excelência, o "tempo estético", estático, da hipótese imaginária equaciona todos os possíveis: perto $e$ longe... Nos termos da teoria estética de Adorno, neste tipo de obras de profundo escopo dialético, "o movimento detido eterniza-se no instante; porém, o eternizado se aniquila na sua própria redução ao instante" (25). Eis o diálogo postulado pelo conto crítico.

Esse tempo matutado por Rosa seria, portanto, em termos de "Páramo", o "tempo $t$ " (16.17) para o qual a própria incerteza é a matéria da qual ele é feito. Esse tempo, ao qual refere-se o texto rosiano, é uma temporalidade trilhável naquela hipótese que faria coincidir trajetória e trajeto, na encruzilhada crítica, na concruz dos caminhos narrativos. Para o pensamento bergsoniano, a "simultaneidade no instante" e a "simultaneidade de fluxo" são coisas diversas, embora se complementem reciprocamente. Precisa-se da primeira, para assinalar, ao longo da nossa própria duração, as simultaneidades. Sem isso, opina o filósofo francês, "haveria ali uma medida qualquer, chegaríamos a um número $t$ representando o que for, e nós não pensaríamos no tempo" (26). O ensejo de Rosa, sabe-se, é se cogitar nele.

Guimarães Rosa "traduz tudo em termos de não-tempo" ("Em-Cidade", in Ave, Palavra, p. 119). "Páramo" não acontece no tempo, mas "eternamente" (22.12). Nessa procura, os problemas histórico e artístico se anulam mutuamente. $\mathrm{O}$ relato não conta uma estória, mas consta de um conjunto de "situações textuais", isoláveis, dele e da mera seqüência. Isto é, situações carentes tanto de representação definida, quanto de substância narrativa concreta. Em cada uma das alternativas desse tempo paradoxal, dialético, o leitor deve optar por todas as possibilidades. Procurando ora se orientar nalguma delas (se preocupado pelo fio narrativo), ora não eliminando nenhuma delas (se satisfeito pelo potencial poético). Ficam ao seu dispor "intensidades de imobilidade diversas" (27), cujo amálgama espaço-temporal só se levaria a efeito no pensamento. E só quando este acionasse o seu sistema. O propósito essencial dessa hipótese estética cunhada por Rosa seria, pois, o de "rejeitar o sistema privilegiado" (28) dos gêneros: o conhecido turbilhão nominalista, seja da narrativa seja da poesia convencionais. 